\title{
Estimation of allele and haplotype frequencies for 23 YSTR markers in the Lebanese population
}

\begin{abstract}
Y-STR analysis may in certain cases complement the autosomal STR markers in forensic, investigations, kinship testing and human identification. Hence, it would be informative to assess the probability of occurrence of the Y-STR haplotype in the Lebanese population where. This study aimed at estimating the Lebanese Y-STR allele and haplotype frequencies in 502 non-related males using the Y-filer Kit (Applied Biosystems) which includes the nine minimal Y-STR haplotype: DYS19, DYS390, DYS391, DYS392, DYS393, DYS389I/II, DYS385a/b plus 14 other Y-STR loci: DYS437, DYS438, DYS439, DYS456, DYS456, DYS448, Y-GATA-H4, DYS576, DYS570, DYS549, DYS643, DYS533 and DYS481. All 23 Y-STR loci were highly polymorphic with the marker DYS385a/b being the most polymorphic. 489 different haplotypes were defined where $476(94.8 \%)$ carried a unique haplotype and the most common haplotypes appeared twice. This database has a discrimination capacity of $97.4 \%$ and a haplotype diversity of $0.9999 \%$. The obtained data serves as an essential pre-requisite for using Y-chromosomal STR in routine forensic practice in the Lebanese population where the endogamy rate average is $88 \%$.
\end{abstract}

Keywords: Y-chromosome, Y-STR, haplotype, allele, frequency, Lebanese population
Volume 5 Issue 2 - 2017

\author{
Mouayyad AIAzem, ' Ansar El Andari, ${ }^{1,2}$ Issam \\ Mansour' \\ 'Molecular Biology Laboratory, American University of Science \\ and Technology, Lebanon \\ ${ }^{2}$ School of Criminal Justice, University of Lausanne, Switzerland
}

Correspondence: Issam Mansour, Molecular Biology

Laboratory, Faculty of Health Sciences, American University of Science and Technology, Ashrafieh, Lebanon, Tel 96I 03-649207, Email fhs@aust.edu.lb

Received: July 20, 2017 | Published: July 26, 2017

\section{Introduction}

Forensic investigation and human identification using DNA testing have come into popularity in the late 1980 's $\mathrm{s}^{1-7}$ with the most commonly used polymorphic markers in forensic casework lay on the autosomal short tandem repeats (STR). In some case work, such as in rape cases or DNA mixture, autosomal STRs fail to be informative. ${ }^{8,9}$ The amplification of Y chromosome STR markers provides an attractive alternative ${ }^{10,11}$ which will amplify only the male DNA in the mixture. There is a wide range of other applications to Y-STR profiling namely patrinlinealrelationships, familial search, ${ }^{12}$ disaster victim identification, ${ }^{13}$ studies of geographical or ethnic origins, archeogenetics, ${ }^{14,15}$ genealogical studies, reconstruction of human history and investigation of cases involving mixtures. ${ }^{16} \mathrm{Certain}$ limitations have constrained the use of Y-STR since it is always in a haploid state ${ }^{2}$ most of the polymorphisms lay in the non-recombining region of the Y-chromosome $(\mathrm{NRY})^{17}$ and the NRY is inherited unchanged through paternal lineages unless a meiotic mutation occurs. Consequently, when a reference Y-STR profile matches a profile obtained from a crime scene trace, all members of the paternal lineage would probably match too, in addition to any male who shares a more distant paternal ancestry with the person to whom belongs the reference sample. ${ }^{18}$ The probability of sharing Y-STR profiles increases in isolated populations. ${ }^{19}$

According to Balding et al., ${ }^{20}$ it is possible that within a suspect's sub-population, the crime scene DNA profile may be more common than in the wider population. Lebanon is a country with a population of around 4.5 million and a geographical area of 10,452 $\mathrm{Km}^{2}$ situated on the eastern coast of the Mediterranean Sea. Several waves of immigration were observed in this area such as the Muslim expansion in the $7^{\text {th }}$ century, the Crusades between the $11^{\text {th }}$ and $13^{\text {th }}$ centuries and Ottoman Empire expansion in the $16^{\text {th }}$ century followed by the Armenian exode, French protectorate and the Palestinian exode in the $20^{\text {th }}$ century. All these historical events led to the diversity in terms of religious belongings to 18 different religious communities with an average rate of endogamy of $88 \% .{ }^{21}$ Endogamy is a widely common practice and has an effect on differentiation resulting from genetic stratification by genetic relatedness. Consequently, population allele and haplotype frequencies are essential for a more accurate use of Y-STR since they provide the basis for random match probability calculations in forensics and human identification. ${ }^{2}$ Inter-population variability seems to be more pronounced in the case of Y-chromosome than for the unlinked autosomal markers, which makes the definition of local databases essential for the use of Y-specific markers. ${ }^{22}$ In a crime or paterliniary study involving a suspect from an isolated subpopulation group or geographically isolated region, the appropriate frequencies can be used in generating a random match probability. ${ }^{19}$ Such data are not available for the Lebanese population, and it would be highly informative to assess these frequencies where endogamy is a widely spread practice. The subject of the present work is to compile Y-chromosome allele and haplotype frequencies of natives from Lebanon using 23 Y-chromosome STR markers, calculate rate of occurrence and determine match probability in forensic casework.

\section{Material and methods}

\section{DNA extraction}

Samples were collected from 502 non-related male individuals selected based on their geographic and religious distribution which represents the Lebanese population according to the Ministry of Interior and Municipalities in 2009 as described by El Andari et al., ${ }^{23}$ Samples collected were either EDTA blood $(\mathrm{n}=346)$ or buccal swabs $(\mathrm{n}=156)$ (from right cheek, left cheek and tongue). DNA was extracted from whole blood leukocytes using the salting out method and from buccal swabs using a modified phenol-chloroform method. Samples were quantified using Nanodrop 2000 (Thermo Fisher Scientific Inc.) and diluted accordingly to approximately $1 \mathrm{ng} / \mu \mathrm{l}$. 


\section{PCR amplification}

DNA amplification of the 23 Y-STR loci was performed using two commercial kits: the Applied Biosystems Y-Filer ${ }^{\mathbb{B}}$ multiplex PCR Amplification kit (Applied Biosystems, Foster City, CA) and the PromegaPowerPlex ${ }^{\circledR}$ Y23 System (Promega, Madison, USA). The 23 Y-STR systems include the 11 core loci recommended by the SWGDAM: DYS19, DYS385a/b, DYS389I/II, DYS390, DYS391, DYS392, DYS393, DYS438, DYS439 and additional markers DYS437, DYS448, DYS456, DYS458, DYS635 and Y-GATA-H4. Amplifications typically contained $0.5-1.0 \mathrm{ng}$ of extracted DNA. PCR reactions were carried out on GeneAmp PCR System 9700 (Applied Biosystems) using the cycling conditions as described in the manufacturers' instructions. ${ }^{24,25}$

\section{DNA typing}

Electrophoretic separation and detection were performed using the ABI PRISM ${ }^{\circledR} 3130$ Genetic Analyzer 4-capillary array system (ABI Prism 3130 Data Collection Software version 3.0) (Applied Biosystems, Foster City, CA). Size calling was performed using the GeneScan-500 Internal Lane Size Standard (LIZ-500) (Applied Biosystems) and CC5 Internal Lane Standard 500 (Promega, Madison, USA). Genotyping was performed by comparison with the provided allelic ladder and using Genemapper v4.0 (Applied Biosystems).

\section{Statistical analysis}

Y-STR data from the GeneScan ${ }^{\circledR}$ software was transferred to an in-house software named Forensic Information Management System (FIMS) to estimate the allele frequencies for the 23 Y-STR systems. Gene diversity (GD) was calculated for each Y-STR according to the formula supplied by $\mathrm{Nei}^{26} \mathrm{GD}=(\mathrm{n} / \mathrm{n}-1)\left(1-\Sigma \mathrm{pi}^{2}\right)$. Haplotype diversity (HD) was also computed with the same equation using haplotype frequencies instead of allele frequencies. Unique haplotypes (UH), random match probability (RMD) and discrimination capacity (DC $)^{27,28}$ were also calculated for the obtained data. Y-STR alleles are inherited in haplotypes, so their individual frequencies cannot be the product of the combined frequencies. ${ }^{29}$ Haplotype frequency was obtained using the counting method. ${ }^{30}$ Values were confirmed using Arlequin v3.5 software. ${ }^{31}$

\section{Quality control}

A proficiency testing quality control check was performed in conjunction with submission to the YHRD.org database. ${ }^{32}$

\section{Results and discussion}

\section{Lebanese Y-STR allele frequencies}

Allele frequencies for 23 Y-STR markers were estimated in the Lebanese population (Table 1). 23 Y-STR systems were amplified, yet they were designated as 22 systems because of the duplicated DYS 385 system which is a multi-copy Y-STR system that represents variations at two loci simultaneously, thus were analyzed as a phenotype. ${ }^{33}$ Table 2 represents the allele frequencies for system DYS385a/b in the Lebanese population.Micro-variants (partial alleles) were observed in several occasions in system DYS458 (Table 1) whereby individuals exhibited an addition or deletion of 2 bp (alleles 16.2, 17.2, 18.2, 19.2, 20.2, 21.2, and 23.2). New and rare alleles were also documented (Table 3) according to published results in the NIST Standard Reference Database. ${ }^{34}$ Null alleles and multiple peaks were reported at a number of loci (Table 3). The null alleles will be investigated and confirmed in the near future using a second set of primers. As observed previously, ${ }^{35,36}$ DYS19 exhibits a relatively high frequency of duplications (reported to be $0.12 \%$ ).

Table 2 Allele frequencies for multi-copy system 385a/b

\begin{tabular}{|c|c|c|c|c|c|c|c|c|}
\hline System & Allele & $(N=502)$ & System & Allele & $(N=502)$ & System & Allele & $(N=502)$ \\
\hline \multirow[t]{18}{*}{ DYS385a/b } & $10-O c t$ & 0.004 & DYS385a/b & $13 / 13$ & 0.02 & DYS385a/b & $15 / 17$ & 0.008 \\
\hline & I5-Oct & 0.002 & & $13 / 14$ & 0.02 & & $15 / 18$ & 0.006 \\
\hline & II-Nov & 0.002 & & $13 / 15$ & 0.048 & & $15 / 19$ & 0.014 \\
\hline & 12-Nov & 0.008 & & $13 / 16$ & 0.056 & & $15 / 20$ & 0.002 \\
\hline & I3-Nov & 0.012 & & $13 / 17$ & 0.068 & & $15 / 22$ & 0.002 \\
\hline & I4-Nov & 0.062 & & $13 / 18$ & 0.09 & & $16 / 16$ & 0.028 \\
\hline & I5-Nov & 0.02 & & $13 / 19$ & 0.05 & & $16 / 17$ & 0.036 \\
\hline & 16-Nov & 0.008 & & $13 / 20$ & 0.006 & & $16 / 18$ & 0.02 \\
\hline & 17-Nov & 0.006 & & $|3 / 2|$ & 0.004 & & $16 / 19$ & 0.006 \\
\hline & I8-Nov & 0.002 & & $14 / 14$ & 0.018 & & $17 / 17$ & 0.012 \\
\hline & 12-Dec & 0.012 & & $14 / 15$ & 0.014 & & $17 / 18$ & 0.008 \\
\hline & 13-Dec & 0.012 & & $14 / 16$ & 0.054 & & $17 / 19$ & 0.006 \\
\hline & I4-Dec & 0.032 & & $14 / 17$ & 0.028 & & $18 / 18$ & 0.012 \\
\hline & I5-Dec & 0.012 & & $14 / 18$ & 0.038 & & $18 / 19$ & 0.012 \\
\hline & 16-Dec & 0.01 & & $14 / 19$ & 0.014 & & $18 / 20$ & 0.006 \\
\hline & I7-Dec & 0.018 & & $14 / 20$ & 0.004 & & $19 / 19$ & 0.012 \\
\hline & 18-Dec & 0.024 & & $15 / 15$ & 0.012 & & $19 / 20$ & 0.002 \\
\hline & 19-Dec & 0.008 & & $15 / 16$ & 0.012 & & $19 / 21$ & 0.002 \\
\hline
\end{tabular}


Table 3 New, rare, multiple and null Y-STR alleles in Lebanese population

\begin{tabular}{|c|c|c|c|c|c|c|c|}
\hline \multirow[b]{2}{*}{ Y-STR system } & \multicolumn{2}{|c|}{ New Alleles } & \multicolumn{2}{|c|}{ Rare Alleles } & \multirow{2}{*}{$\begin{array}{l}\text { Null Alleles } \\
\text { Number of } \\
\text { times observed }\end{array}$} & \multicolumn{2}{|c|}{ Multiple Alleles } \\
\hline & Allele & $\begin{array}{l}\text { Number of } \\
\text { times observed }\end{array}$ & Allele & $\begin{array}{l}\text { Number of } \\
\text { times observed }\end{array}$ & & Allele & $\begin{array}{l}\text { Number of } \\
\text { times observed }\end{array}$ \\
\hline DYS438 & & & 7 & 2 & & & \\
\hline DYS458 & 23.2 & I & & & & & \\
\hline DYS456 & & & 12 & I & & & \\
\hline DYS635 & & & 17 & 3 & & & \\
\hline DYS448 & & & & & I & & \\
\hline DYSI9 & & & & & & 15,16 & 2 \\
\hline
\end{tabular}

\section{Diversity of Y-STR alleles}

In a second step, the gene diversity values of the tested Y-STR systems in Lebanese and Caucasians males were compared (Table 4). ${ }^{33,37,38}$ Systems were ranked according to their gene diversity values. When compared to the Caucasian population similar results were obtained for the two most polymorphic systems (DYS385a/b and DYS458). However, the system with the lowest gene diversity value in each of the Lebanese and Caucasian population groups were attributed to different markers (DYS392 in Lebanese population and DYS393 in Caucasian population), indicating that while some markers could be highly informative and polymorphic in Caucasian they could be of limited value in the analysis of the Lebanese population.

Table 4 Lebanese population gene diversity compared as to the Y-STR systems in the Caucasian population

\begin{tabular}{|c|c|c|c|c|}
\hline System & Lebanese gene diversity & Rank & Caucasians gene diversity & Rank \\
\hline DYS385a/b & 0.964 & 1 & 0.842 & 1 \\
\hline DYS458 & 0.855 & 2 & 0.777 & 2 \\
\hline DYS48I & 0.838 & 3 & 0.72 & 6 \\
\hline DYS570 & 0.814 & 4 & 0.747 & 4 \\
\hline DYS635 & 0.777 & 5 & 0.643 & 11 \\
\hline DYS576 & 0.775 & 6 & 0.768 & 3 \\
\hline DYS643 & 0.762 & 7 & 0.625 & 12 \\
\hline DYS389II & 0.75 & 8 & 0.676 & 9 \\
\hline DYS390 & 0.676 & 9 & 0.708 & 7 \\
\hline DYS448 & 0.671 & 10 & 0.596 & 15 \\
\hline DYS456 & 0.649 & 11 & 0.722 & 5 \\
\hline DYS533 & 0.648 & 12 & 0.588 & 17 \\
\hline DYS439 & 0.648 & 13 & 0.648 & 10 \\
\hline DYS438 & 0.645 & 14 & 0.59 & 16 \\
\hline DYSI9 & 0.636 & 15 & 0.509 & 21 \\
\hline DYS549 & 0.627 & 16 & 0.68 & 8 \\
\hline DYS393 & 0.599 & 17 & 0.381 & 22 \\
\hline DYS3891 & 0.579 & 18 & 0.52 & 20 \\
\hline Y-GATA-H4 & 0.562 & 19 & 0.599 & 14 \\
\hline DYS437 & 0.557 & 20 & 0.576 & 18 \\
\hline DYS39I & 0.495 & 21 & 0.546 & 19 \\
\hline DYS392 & 0.438 & 22 & 0.604 & 13 \\
\hline
\end{tabular}


Taking into consideration the high rates of endogamy in the Lebanese population, the gene diversity for the different Lebanese sub-populations was calculated to attempt and assess whether genetic differences between different religious sub-populations existed. Results showed that a marker may have variable polymorphisms among these subpopulations (Table 5). For example DYS448 could discriminate $72.5 \%$ of the individuals in the Muslim Shiite subpopulation; however, it could only discriminate $59.1 \%$ of individuals belonging to the Druze subpopulation. Another variation was recorded in system DYS392 between Armenian Orthodox (73\%) which greatly differed from Christian Orthodox (30\%). The latter example particularly shows the effect of endogamous marriages whereby both communities were Orthodox, yet they still differed in terms of marker gene diversity since Armenian Orthodox and Christian Orthodox do not intermingle.

Table 5 Lebanese population and the major subpopulations (whereby $n \geq 15$ ) gene diversity values

\begin{tabular}{|c|c|c|c|c|c|c|c|c|}
\hline & $\begin{array}{l}\text { Lebanese } \\
\text { population }\end{array}$ & $\begin{array}{l}\text { Muslim } \\
\text { sunnite }\end{array}$ & $\begin{array}{l}\text { Muslim } \\
\text { shiite }\end{array}$ & $\begin{array}{l}\text { Christian } \\
\text { maronite }\end{array}$ & $\begin{array}{l}\text { Christian } \\
\text { catholic }\end{array}$ & $\begin{array}{l}\text { Christian } \\
\text { orthodox }\end{array}$ & $\begin{array}{l}\text { Armenian } \\
\text { orthodox }\end{array}$ & Druze \\
\hline Sample Size & 502 & 140 & 137 & 108 & 26 & 30 & 16 & 32 \\
\hline DYSI9 & 0.635 & 0.69 & 0.583 & 0.637 & 0.569 & 0.628 & 0.717 & 0.639 \\
\hline DYS389I & 0.577 & 0.513 & 0.559 & 0.643 & 0.532 & 0.591 & 0.7 & 0.667 \\
\hline DYS389II & 0.75 & 0.728 & 0.726 & 0.78 & 0.683 & 0.756 & 0.767 & 0.681 \\
\hline DYS390 & 0.676 & 0.675 & 0.628 & 0.711 & 0.68 & 0.687 & 0.717 & 0.625 \\
\hline DYS39I & 0.495 & 0.521 & 0.489 & 0.523 & 0.394 & 0.453 & 0.5 & 0.476 \\
\hline DYS392 & $0.44 I$ & 0.404 & 0.447 & 0.48 & 0.351 & 0.306 & 0.725 & 0.544 \\
\hline DYS393 & 0.599 & 0.644 & 0.575 & 0.565 & 0.631 & 0.57 & 0.625 & 0.643 \\
\hline DYS437 & 0.557 & 0.468 & 0.58 & 0.634 & 0.44 & 0.549 & 0.675 & 0.542 \\
\hline DYS438 & 0.643 & 0.542 & 0.663 & 0.662 & 0.683 & 0.593 & 0.775 & 0.639 \\
\hline DYS439 & 0.648 & 0.645 & 0.627 & 0.66 & 0.714 & 0.57 & 0.7 & 0.669 \\
\hline DYS448 & 0.671 & 0.618 & 0.725 & 0.683 & 0.532 & $0.64 I$ & 0.675 & 0.591 \\
\hline DYS456 & 0.647 & 0.694 & 0.614 & 0.673 & 0.397 & 0.72 & 0.617 & 0.623 \\
\hline DYS458 & 0.857 & 0.872 & 0.835 & 0.835 & 0.886 & 0.857 & 0.792 & 0.766 \\
\hline DYS635 & 0.777 & 0.771 & 0.771 & 0.774 & 0.772 & 0.779 & 0.808 & 0.81 \\
\hline Y-GATA-H4 & 0.563 & 0.538 & 0.568 & $0.54 \mathrm{I}$ & 0.603 & 0.618 & 0.633 & 0.591 \\
\hline DYS385a/b & 0.964 & 0.96 & 0.956 & 0.961 & 0.963 & 0.986 & 0.958 & 0.96 \\
\hline DYS570 & 0.815 & 0.805 & 0.782 & 0.819 & 0.822 & 0.848 & 0.792 & 0.891 \\
\hline DYS576 & 0.774 & 0.773 & 0.803 & 0.753 & 0.766 & 0.743 & 0.533 & 0.647 \\
\hline DYS48I & 0.838 & 0.856 & 0.801 & 0.829 & 0.886 & 0.86 & 0.792 & 0.875 \\
\hline DYS643 & 0.762 & 0.736 & 0.751 & 0.773 & 0.846 & 0.777 & 0.708 & 0.732 \\
\hline DYS533 & 0.648 & 0.619 & 0.642 & 0.674 & 0.674 & 0.609 & 0.725 & 0.677 \\
\hline DYS549 & 0.627 & 0.617 & 0.633 & 0.655 & 0.502 & 0.625 & 0.4 & 0.714 \\
\hline
\end{tabular}

This demonstrated possible heterogeneity of allele frequencies across the different Lebanese sub-populations and is in agreement with previous population studies which showed that sub-populations exhibit greater differentiation at certain loci with the possibility of identifying new and unique alleles. ${ }^{39}$

\section{Lebanese Y-STR haplotype frequency}

The haplotype diversity (HD) in the Lebanese population was $0.9999 \%$. A total of 489 distinct haplotypes were observed in the total data set $(n=502)$ with 476 haplotypes being unique and 13 haplotypes observed more than once (Table 6). Different case scenarios were seen with the 13 common haplotypes shared by two individuals each: individuals either originated from the same religious community and geographical area, the same religious community but originated from different geographical areas or vice-versa or belonged to different religious communities as well as to different geographical origins. Results showed that Y-STR haplotypes were not restricted to members originating from the same family. Individuals from distinct geographical areas and/or religious communities shared a common haplotype. These cases could be explained by common ancestry whereby non-related individuals may have had a distant common ancestor and common haplotypes were transmitted from a distant common ancestor without mutation. Haplotype diversity (HD), 
discrimination capacity (DC), unique haplotypes (UH) and random match probability (RMP) calculations were performed to determine how common a Y-STR haplotype occurred in the population and how frequent a random match could occur between two non-related individuals (Table 7).

The occurrence of common haplotypes raises the question of how often a haplotype is present in the population and what are the chances of a match when used in forensic cases. The frequency of the most common haplotype $(\mathrm{n}=2)$ was $0.009 \%$ meaning that the probability of finding an individual sharing this haplotype is one in 111 (Table 8). When comparing a haplotype occurrence within the total population and sub-population datasets, the haplotype frequency and consequently the discrimination capacity varied. The haplotype frequency decreased in the sub-populations leading to a lower discrimination capacity and higher match probability. A match frequency of only one in 111 in the total population has a match frequency of one in 30 among Muslim Sunnites and of one in seven among Druze. The match probability varies greatly when using total population $\mathrm{v} / \mathrm{s}$ sub-population datasets.

Table 6 Haplotype diversity and number of distinct haplotypes in the Lebanese population

\begin{tabular}{lllll}
\hline Population & $\begin{array}{l}\text { No. of distinct } \\
\text { haplotypes }\end{array}$ & $\begin{array}{l}\text { No.pf haplotypes } \\
\text { observed once }\end{array}$ & $\begin{array}{l}\text { No. of haplotypes observed } \\
\text { more than once }\end{array}$ & Haplotype diversity \\
\hline Lebanese $(n=502)$ & 489 & 476 & 13 & 0.9999 \\
\hline
\end{tabular}

Table 7 Statistical indices for the Lebanese population

\begin{tabular}{|c|c|c|c|c|}
\hline \multicolumn{5}{|c|}{ Lebanese population } \\
\hline & (N=502) HD (\%) & UH & RMP (\%) & DC (\%) \\
\hline 23 Y-STR & 0.9999 & 476 & 0.0001 & 97.4 \\
\hline
\end{tabular}

Table 8 Rate of match of the most frequent haplotype in the total population and in the subpopulation where each haplotype occurred

\begin{tabular}{llll}
\hline Religious community & $\begin{array}{l}\text { Haplotype frequency } \\
\text { (occurrence) }\end{array}$ & $\begin{array}{l}\text { Match frequency in total } \\
\text { population }\end{array}$ & $\begin{array}{l}\text { Match frequency in sub- } \\
\text { population }\end{array}$ \\
\hline Muslim Sunnite $(\mathrm{n}=140)$ & 2 & $\mathrm{I} / \mathrm{II}$ & $30-\mathrm{Jan}$ \\
Druze $(\mathrm{n}=32)$ & 2 & $\mathrm{I} / \mathrm{II}$ & 7 -Jan \\
\hline
\end{tabular}

\section{Conclusion}

Allele and haplotype frequencies for the Lebanese population were estimated. The study showed that Y-STR markers exhibit possible genetic Y-chromosomal heterogeneity within and between populations and would seem to be very useful to trace back human evolutionary processes at a historical time-scale. While many Y-STR markers were highly discriminative in the Lebanese population; others were less discriminative such as system DYS392. In the future, if specific kits were to be developed for the Lebanese population and other closely related populations with similar socio-economic characteristics, we may omit this system (DYS392) and other similar low discriminative markers. Match probability differed when comparing the national database with the respective sub-population database, thus the question that raises itself which dataset to use in case of a match profile in a forensic case. In order to properly assess this issue, more samples from each subpopulation should be tested in order to determine whether allele and haplotype frequencies along with the match probability would change.

Evaluating possible Lebanese genetic sub-structures will be essential. If sub-structures exists, they should be accounted for when producing the strengths of the DNA profile evidence in Y-STR analysis whereby theta values will be calculated and incorporated in calculations. These criteria should be used to validate and evaluate Y-STR haplotype frequencies used in match probability calculations in forensic cases, human identification and kinship studies. Results in this study showed that there is a certain level of endogamy in the Lebanese population. Hence, for better assessment of the effect of endogamy a further Y-23 study will be performed on random villages with known high endogamous rates. This article follows the guidelines for publication of population data requested by the journal..$^{40}$

\section{Acknowledgments}

The authors wish to thank and acknowledge all the Lebanese volunteers for participating in this study, and Applied Biosystems and Promega for granting and supporting this project. Also Mrs. Andary's has also an equal contribution of this manuscript.

\section{Conflicts of interest}

The author declares there are no conflicts of interest.

\section{References}

1. Edwards A, Civitello A, Hammond HA, et al. DNA typing and genetic mapping with trimeric and tetrameric tandem repeats. Am J Hum Genet. 1991;49(4):746-756.

2. Weber JL, May PE. Abundant class of human DNA polymorphisms which can be typed using the polymerase chain reaction. Am J Hum Genet. 1989;44(3):388-396.

3. Decker AE, Kline MC, Vallone PM, et al. The impact of additional Y-STR loci on resolving common haplotypes and closely related individuals. Forensic Sci Int Genet. 2007;1(2):215-217.

4. Litt M, Luty JA. A hypervariable microsatellite revealed by in vitro amplification of a dinucleotide repeat within the cardiac muscle actin gene. Am J Hum Genet. 1989;44(3):397-401. 
5. Chakraborty R, Kidd K. The utility of DNA typing in forensic work Science. 1991;254(5039):1735-1739.

6. Caskey CT, Hammond HA. Forensic use of short tandem repeats via PCR. Advances in forensic haemogenetics. 4th edn. Springer, Germany. $1992 ; 18-25$

7. Roewer L Epplen JT. Rapid and sensitive typing of forensic stains by PCR amplifications of polymorphic simple repeat sequences in case work. Forensic Sci Int. 1992;53(2):163-171.

8. Koblinsky LF, Liottie TF, Oeser Sweat J. Forensic DNA Analysis Methods. In DNA: Forensic and Legal Applications. John Wiley and Sons, USA. 2005;1-114.

9. Parson W, Niederstatter H, Kochl S, et al. When autosomal short tandem repeats fail: optimized primer and reaction design for Y-chromosome short tandem repeat analysis in forensic casework. Croat Med J. 2001;42(3):285-287.

10. Martin P, Albarran C, Garcia O, et al. Application of Y-STR analysis to rape cases that cannot be solved by autosomal analysis. Prog in Forensic Gen. 2000;526-528.

11. Jobling MA, Tyler Smith C. Fathers and sons: the Y chromosome and human evolution. Trends Genet. 1995;11(11):449-456.

12. Casanova M, Leroy P, Boucekkine C, et al. A human Y-linked DNA polymorphism and its potential for estimating genetic and evolutionary distance. Science. 1985;230(4732):1403-1406.

13. Calacal GC, Delfin FC, Tan MM, et al. Identification of exhumed remains of fire tragedy victims using conventional methods and autosomal/Ychromosomal short tandem repeat DNA profiling. Am J ForensicMed Pathol. 2005;26(3):285-291.

14. Underhill PA, Shen P, Lin AA, et al. Y chromosome sequence variation and history of human populations. Nat genet. 2000;26(3):358-361.

15. Daniels DL, Hall AM, Ballantyne J. SWGDAM Development Validation of a 19-Locus Y-STR System for Forensic Casework. J Forensic Sci. 2004;49(4):668-683.

16. White PS, Tatum OL, Deaven LL, et al. New male-specific microsatellite markers from the human Y chromosome. Genomics. 1999;57(3):433-437.

17. Jobling MA, Pandya A, Tyler Smith C. The Y chromosome in forensic analysis and paternity testing. Int J Legal Med. 1997;110(3):118-124.

18. Prinz M. Advantages and disadvantages of Y-short tandem repeat testing in forensic casework. Forensic Sci Rev. 2003;15(2):191-198.

19. Butler JM. Biology, technology, and genetics of STR. In Forensic DNA Typing. 2nd edn. Elsevier Academic Press, UK. 2005;1-660.

20. Balding DJ, Nichols RA. DNA profile match probability calculations: how to allow for population stratification, relatedness, database and single bands. Forensic Sci Int. 1994;64(2-3):125-140.

21. Khlat M, A Khudr. Religious endogamy and consanguinity in marriage patterns in Beirut, Lebanon. Soc Biol. 1984;33(1-2):138-145.

22. Kayser M, Krawezak M, Excoffier L, et al. An extensive analysis of Y-chromosomal microsatellite haplotypes in globally dispersed human populations. Am J Hum Genet. 2001;68(4):990-1018.
23. El Andari A, Othman H, Taroni F, et al. Population genetic data for 23 STR markers from Lebanon. Forensic Sci Int Genet. 2013;7(4):108-113.

24. AmpFlSTR Yfiler PCR Amplification Kit User's Manual. Applied Biosysytems, USA. 2006;1-234.

25. PowerPlex ${ }^{\circledR}$ Y23 System Kit MSDS Manual.

26. Nei M. Molecular Evolutionary Genetics. 1st edn. Columbia University Press, USA. 2006.

27. Kayser M, Caglià A, Corach D, et al. Evaluation of Y-chromosomal STRs: a multicenter study. Int J Legal Med. 1997;110(3):125-133.

28. Schoske R, Vallone PM, Kline MC, et al. High throughput Y-STR typing of U.S. populations with 27 regions of the $\mathrm{Y}$ chromosome using two multiplex PCR assays. Forensic Sci Int. 2004;139(2-3):107-121.

29. Charaborty R, Jin L, Zhong Y, et al. On allele frequency computation from DNA typing data. Int J Legal Med. 1993;106(2):103-106.

30. Holland MM, Parsons TJ. Mitochondrial DNA sequence analysis - validation and use for forensic casework. Forensic Sci Rev. 1999;11(1):21-50.

31. Excoffier L, Laval G, Schneider S. Arlequin ver. 3.0: An integrated software package for population genetics data analysis. Evol Bioinform Online. 2005; 1:47-50.

32. Willuweit S, Roewer L. Y chromosome haplotype reference database (YHRD): Update. Forensic Sci Int Genet. 2007;1(2):83-87.

33. Mulero JJ, Chang CW, Calandro LM, et al. Development and validation of the AmpFISTR Yfiler PCR amplification kit: a male specific, single amplification 17 Y-STR multiplex system. J Forensic Sci. 2006;51(1):64 75 .

34. Butler JM, reeder DJ. Short Tandem Repeat DNA Internet DataBase. National Institute of Standards and technology, USA. 2017.

35. Butler JM, Schoske R. Duplication of DYS19 flanking regions in other parts of the Y-chromosome. Int J Legal Med. 2004;183(3):178-183.

36. Kayser M, Sajantila A. Mutations at Y-STR loci: Implications for paternity testing and forensic analysis. Forensic Sci Int. 2001;118(2-3):116-121.

37. John MB, Decker AE, Vallone PM, et al. Allele frequencies for 27 Y-STR loci with U.S. Caucasian, African American, and Hispanic samples. Forensic Sci Int. 2006;156(2-3):250-260.

38. Hanson EK, Berdos PN, Ballantyne J. Testing and evaluation of 43 "Noncore" Y chromosome markers for forensic casework applications. $J$ Forensic Sci. 2006;51(6):1298-1314.

39. Zhivotovsky LA, Ahmed S, Wang W, et al. The forensic DNA implications of genetic differentiation between endogmaous communities. Forensic Sci Int. 2001;119(3):269-272.

40. Lincolin P, Carracedo A. Publication of population data of human polymorphisms. Forensic Sci Int. 2000;110(1):3-5. 